\title{
ARAŞTIRMA/RESEARCH
}

\section{Klasik bale eğitimi alacak öğrencilerin somatotip analizi}

\author{
Somatotype analysis of students who will be trained for classical ballet \\ Ayşe Gül Kabakc1 ${ }^{1}$, Ahmet Hilmi Yücel ${ }^{1}$ \\ ${ }^{1}$ Cukurova University Faculty of Medicine, Department of Anatomy, Adana, Turkey
}

Abstract

Objective: The aim of this study is to analysis the body type for classsical ballet training.

Material and Method: In the 2013-2014 academic year Cukurova University State Conservatory Ballet Main Art Branch recieved 8-11-year-old students admitted to study ballet training, compared to students who were not accepted by the accepted students. Convenient and inconvenient students for ballet education were identified as two study groups. While conevient experimental group, inconvenient students were evaluated as control group. This study ballet students determine their body type and includes anthropometric measurements to evaluate objectively the criteria for ballet training. In determining the Heath-Carter body type classification is used.

Results: In our study, 51 female students who applied to Cukurova University State Conservatory Ballet Main Branch for education were enrolled. As 31 girls were convenient for ballet education, 20 girls were not. While the average of age, height and weight measurements of convenient students were $9.51 \pm 0.67,1.38 \pm 0.07 \mathrm{~m}$ and $30.03 \pm 4.85 \mathrm{~kg}$ respectively, the same dimensions in inconvenient students, $10.20 \pm 0.89,1.43 \pm 0.10 \mathrm{~m}$ and $39.06 \pm 6.94 \mathrm{~kg}$ respectively. Measurements of diameter, circumference and subcutaneous fat thickness were found less for convenient students. Major body type of convenient students was identified as mesomorph, whereas major body type of inconvenient students was identified as endomorphy.

Conclusion: These parameters used in convenience for classical ballet education were evaluated objectively. The observations presented in this study have defined physical features and need to be taken into consideration for evaluate and guidelines for determine the deficiency in literature..

Key words: Ballet, ballet student, physical features, anthropometry, flexibility
2016;41(4):: 744-750.

Öz

Amaç: Bu çalışmanın amacı klasik bale eğitimi alacak öğrencilerin somatotip analizinin yapılmasıdır.

Gereç ve Yöntem: 2013-2014 eğitim öğretim döneminde Cukurova Üniversitesi Devlet Konservatuvarı Bale Anasanat Dalı'na bale eğitimi için başvuran 8-11 yaş arası öğrenciler çalışmaya alınıp, kabul edilen öğrenciler ile kabul edilmeyen öğrenciler karşılaştırılmıştır. Baleye uygun bulunanlar ile uygun bulunmayanlar iki çalş̧ma grubu olarak belirlenip, uygun bulunanlar deney grubu, uygun bulunmayanlar ise kontrol grubu olarak değerlendirildi. $\mathrm{Bu}$ çalışma bale öğrencilerinin vücut tipini belirleyen ve bale eğitimi için gerekli kriterleri objektif olarak değerlendiren antropometrik ölçümleri kapsamaktadır. Vücut tipinin belirlenmesinde Heath-Carter sınıflaması kullanılmıştır. Bulgular: Çalısmamıza, Çukurova Üniversitesi Devlet Konservatuvarı Bale Anasanat Dalı'na bale eğitimi için başvuran 8-11 yaş arası $51 \mathrm{k} 1 z$ öğrenci dahil edildi. Katılımcılardan $31 \mathrm{klz}$ öğrenci bale eğitimine uygun bulunup, $20 \mathrm{k} 1 z$ öğrenci uygun bulunmamıștır. Uygun bulunanların yaş ortalaması; $9.51 \pm 0.67$, boy uzunluğu ortalamas1; $1.38 \pm 0.07 \mathrm{~m}$ ve vücut ağırlığ 1 ortalamas1; $30.03 \pm 4.85 \mathrm{~kg}$ iken, uygun bulunmayan öğrencilerin yaş ortalamasi; $10.20 \pm 0.89$, boy uzunluğu ortalamasi; $1.43 \pm 0.10 \mathrm{~m}$, ve vücut ağırlığı ortalaması; $39.06 \pm 6.94 \mathrm{~kg}$ olarak bulunmuştur. Çap, çevre ve deri altı yağ dokusu kalınlığı ölçümleri uygun bulunan öğrencilerde daha düşük bulunmuştur. Uygun bulunanlarda baskın vücut tipi mezomorf iken uygun bulunmayanlarda ise endomorf olarak bulunmuştur.

Sonuç: Klasik bale eğitimine uygun vücut tipini belirleyen parametreler objektif olarak değerlendirilmiştir. Yapılan bu çalışmanın literatürdeki eksikliklerin giderilmesine katkı sağlayacağı düşünülmektedir.

Anahtar kelimeler: Antropometri, bale, balerin, HeathCarter, somatotip. 


\section{GİRİŞ}

Klasik bale eğitimi küçük yaşlardan itibaren uzun yıllar süren yoğun, disiplinli bir çalışma programı içerir. Bu eğitimin sağlıklı bir şekilde üstesinden gelebilmek ve istenilen niteliklere ulaşabilmek için denge, koordinasyon, zihinsel olgunluk, dayanıklilık ve disiplin gibi vasiflara sahip olmak gereklidir ${ }^{1,2}$. Bale sanatı, bir takım fiziksel uygunluk gereksinimlerine sahip olunması gereken bir etkinliktir ${ }^{3,4}$. Bu nedenle bale eğitimine uygun vücut tipinin belirlenmesiyle olası sakatlanmalar önlenip, sağlıklı bir eğitim süreci gerçekleştirilmesi sağlanır. $\mathrm{Bu}$ çalışma da klasik bale eğitimine başlayacak öğrencilerin vücut tiplerinin belirlenmesi amaciyla yapılmıştır.

Bunun için 2013-2014 eğitim-öğretim yllında Çukurova Üniversitesi Devlet Konservatuvarı Bale Anasanat Dalı'na bale eğitimi için başvuran öğrenciler çalışmaya dahil edilip, planlanan antropometrik ölçümlerle değerlendirilmişlerdir. Bu sınavda kabul edilen öğrenciler ile elenen öğrenciler karşılaştırılmıştır. Böylece öğrencilerin fiziksel özellikleri değerlendirilerek, bedenlerini tanımaları, ailelerin farkındalığını artırmak, çocuğun vücuduna karşı olumlu bir tutum takınması, beden kondisyonu hakkında bilinçlenmesi ve sonuçta formunu korumak veya artırmak için hem eğitmenleri hem öğrencileri yönlendirmede faydalı olması amaçlanmıştır. Ayrıca fizik yapının sınıflandırılmasına ait çalışmalara, birçok araştırma sahası ile ilgili büyüme, gelişim, fizyolojik fonksiyonlar, hastalık ve davranış problemlerine 1 şı tutmak ve bale eğitimine uygunlukta gereken vücut tipinin belirlenmesiyle sakatlanmaların önlenmesi amacıyla da yapılmıştır. Çünkü her spor ve sanat dalına özel fiziksel gereksinimler farklıdır ${ }^{1,2}$. Bu çalışmanın amaçlarından bir diğeri ise, bale sanatı odaklı anatomi araştırmalarından elde edilen bilginin, bale eğitiminde nasıl yararlı olacağını göstermektir ${ }^{3,4}$, 5 .

\section{GEREÇ VE YÖNTEM}

Araştırmamız tanımlayıcı bir çalışmadır. 2013-2014 eğitim-öğretim yllında Çukurova Üniversitesi Devlet Konservatuvarı Bale Anasanat Dalı'na bale eğitimi için başvuran 8-11 yaş arası 52 öğrenci çalışmaya dahil edilmiştir fakat bir tane erkek öğrenci başvuru olduğu için çalışmaya dahil edilmemiştir ve çalışma 51 k1z öğrenci ile gerçekleștirilmiștir. Planlanan antropometrik ölçümlerle değerlendirilerek somatotip analizleri yapilıp vücut tipleri belirlenmiştir. Başvuru sınavı sonucunda baleye uygun bulunanlar ile uygun bulunmayanlar iki çalışma grubu olarak atanıp, uygun bulunanlar deney grubu, uygun bulunmayanlar ise kontrol grubu olarak değerlendirilmiştir.

\section{Verilerin elde edilmesi}

Çukurova Üniversitesi Devlet Konservatuvarı Bale Anasanat Dalı'nda yapılan seçimlerde öncelikle adaylara üç gün boyunca profesyonel bale eğitmenleri tarafindan kurs düzenlenmektedir. Bazı temel hareketler, duruşlar ve adımlar uygun kıyafetlerle, müzik eşliğinde stüdyoda öğretilmektedir. Bu eğitimler sırasında öğrencinin koordinasyonu, hareketleri, söylenenleri kavrama kabiliyeti, davranışları, direktiflere uyması, bilişsel ve algısal gelişimi, emosyonel durumu ve heyecanı kontrol durumu değerlendirilmektedir. Ayrıca adayların fiziksel olarak baleye yatkın olup olmadığ1, gösterilen hareketleri yapabilme kabiliyetine göre subjektif olarak bale eğitmenleri tarafindan değerlendirilmektedir. Ayrıca müzik kulağı, ritim duygusu ve istenilen hareketi estetik ve zarif bir şekilde yorumlama yeteneği gözlemlenmektedir. Eğer bale eğitiminde uzman kişilerle doğru bir seçim yapılmazsa, henüz bu konuda bilgi sahibi olmayan bale öğrencisi, bale çalışmasında istenilen koşullar için çaba gösterdikçe, fiziksel engeliyle karşılaşacak ve tekrar eden sakatlanmalarla uzun süren bir meslek hayatına sahip olamayacaktır. Ayrıca kendisini yetersiz hissedip, öz güven ve mutsuzlukla emosyonel gelişimi zarar görecektir. Bu çalışmanın amac1 da bale eğitimi için seçimlerde istenen kriterlerin sadece subjektif değil objektif anatomik değerlendirmelerle de incelenmesidir.

Ölçüm öncesi, deneklere, ölçüm aletleri tanıtılıp, ölçüm prosedürü hakkında bilgi verilmiştir. Ölçümler Çukurova Üniversitesi Devlet Konservatuvarı Bale Anasanat Dalı'nda bulunan stüdyoda gerçekleştirilmiştir. Sınav salonundan çıkan öğrenciler ölçümlerin yapılacağı stüdyoya alınmıştır. Ölçümler ve sonuçları sinav jürisiyle paylaşılmamıştır.

Ölçümlerden önce aileler sözlü ve yazılı olarak bilgilendirilmiş ve aydınlatılmış onam formu imzalatılmıştır. Ayrıca Çukurova Üniversitesi Devlet Konservatuvarı Bale Anasanat Dalı Başkanı'ndan resmi izin alınıp, çalışmamız için Çukurova 
Üniversitesi Tip Fakültesi Girişimsel Olmayan Klinik Araştırmalar Etik Kurulu'ndan onay alınmıştır. Çalışmamız Çukurova Üniversitesi Bilimsel Araştırma Projeleri Koordinasyon Birimi fonu tarafindan TF2-14YL4 numaralı proje olarak desteklenmiştir. Makalede yer alan ölçümler TF214YL4 numaralı yüksek lisans tezinin baz1 parametrelerini içermektedir.

\section{Araç ve gereçler}

Verilerin toplanmasında kullanılan araç ve gereçler ölçümlere başlamadan önce kalibre edilmiştir. Çalışmada yer alan ölçümler ve kullanılan aletler Tablo 1'de özetlenmiştir.

Antropometrik özelliklerin ve vücut tipinin belirlenmesi, klasik bale eğitimi için yetenek seçiminde önemlidir ${ }^{1}$. Bu amaçla yapılan ölçümler aşağıda açıklanmıştır. Bütün ölçümler aynı kişi tarafından yapılmıştır. Denekler mayolu olarak ölçümlere katılmıştır.

Vücut Ağırlığ1 Ölçümü: Denekler tartı üzerine ayakkabısız ve mayolu bir şekilde çıkarak, anatomik pozisyonda ölçümleri alınmıştır ${ }^{6}$.

Beden Kitle Indeksi (BKI): Kilogram cinsinden vücut ağırlı̆̆ının, metre cinsinden boy uzunluğunun karesine bölünmesi ile hesaplanmıştır $\left(\mathrm{kg} / \mathrm{m}^{2}\right)^{7}$.

E1 Bileği Çapı: Radius ve ulna'nın processus styloideus'u arasındaki uzaklık ölçülmüştür ${ }^{8}$.

Humerus Bi-Condyler Çap: Dirsek $90^{\circ}$ fleksiyon pozisyonundayken, humerus'un epicondylus medialis ve epicondylus lateralis'i arasındaki uzaklık ölçülmüştür ${ }^{8}$.

Femur Bi-Condyler Çap: Kişi, dizleri $90^{\circ}$ fleksiyon pozisyonunda otururken, os femoris'in condylus medialis ve condylus lateralis'i arasındaki uzaklık ön yüzden ölçülmüştür ${ }^{8}$.

Ayak Bileği Çap1: Anatomik pozisyonda, vücut ağırlığ1 iki ayağa eşit olarak dağıtılmış bir şekilde malleolus medialis ve malleolus lateralis arasindaki uzaklık ölçülmüştür ${ }^{8}$.

Bel Çevresi: Ölçüm yapılan kişi anatomik pozisyonda olup, subkostal bölge ile crista iliaca arasındaki en dar yerden ölçüm yapılmıştır. Esnek olmayan mezuranın her iki tarafta da yere paralel olmasına ve dokunun sıkıștırılmamasına dikkat edilmiştir. Ölçüm kişinin yan tarafında durularak yapılmıştır ${ }^{8}$.
Kalça Çevresi: Ölçüm yapılan kişi anatomik pozisyonda olup, kişinin yan tarafinda durularak kalçanın en geniş bölgesinden dokuların sıkıştırılmamasına dikkat edilerek ölçüm yapılmıştır ${ }^{8}$.

Uyluk Çevresi: Ölçüm, kişi ayakta, ayakları birbirinden yaklaşık $10 \mathrm{~cm}$ açık ve vücut ağırlığı iki ayağa eşit dağılmışken uyluğun orta kısmından yapılmıştır ${ }^{8}$.

Bacak Çevresi: Ölçüm, kişi ayakta dik durur pozisyonda ve ayakları $20 \mathrm{~cm}$ açık, vücut ağırlığı iki ayağa eşit dağılmış olarak malleolus medialis'in 10-15 $\mathrm{cm}$ üzerinden, kasın en şişkin olduğu yerden yapılmıştır ${ }^{8}$.

\section{Deri Altı Yağ Dokusu Ölçümleri}

Ölçümlerde aşağıdaki hususlara dikkat edilmiştir;

1. Tutma işlemi, ölçüm yapılacak noktanın yaklaşık $1 \mathrm{~cm}$ uzağından, araya kas dokusu girmeyecek şekilde başparmak ile işaret parmağı arasında yapilmışır.

2. Ölçüm tamamlanana kadar tutma işlemi aynı basınç korunarak devam etmiştir.

3. Ölçüm, kaliper ile deri teması olduktan sonra 12 sn içinde gerçekleştirilmiştir.

4. Her bölgeden 2 defa ölçüm alınmıştır.

5. Ölçümler ayakta dik durur pozisyonda ve deneklerin sağ tarafından alınmıştır ${ }^{8}$.

Biceps Yă̆ Ölçümü: Dirsekler ekstansiyon pozisyonunda, kollar gevşek ve gövde yanındayken, antekübital bölge ile omuz arasındaki uzaklığın orta noktasından ölçülmüştür ${ }^{8}$.

Triceps Yağ Ölçümü: Dirsekler ekstansiyon pozisyondayken, kollar gevşek ve gövde yanındayken, acromion ile olecranon arasındaki uzaklığın orta noktasından, vertikal olarak ölçülmüştür ${ }^{8}$.

Subscapular Yağ Ölçümü: Scapula'nın angulus inferior'undan vertebral kenara doğru çizilen 1-2 cm'lik çizgi üzerinden $45^{\circ}$ lik açı ile diagonal olarak ölçülmüştür ${ }^{8}$.

Suprailiak Yağ Ölçümü: Anterior aksiler çizgiden aşağıya doğru indirilen çizginin crista iliaca üzerindeki noktasından $45^{\circ}$ lik açı ile diagonal olarak Ölçülmüştür ${ }^{8}$.

Uyluk Yağ Ölçümü: Ölçüm yapılan taraftaki diz hafif fleksiyon'da, ayağ1 yer ile temasta ve gevşek bir durumda olacak şekilde, articulatio coxae ve 
patellanın proximal kenarı arasındaki uzaklığın orta noktasından vertikal olarak ölçülmüştür ${ }^{8}$.

\section{Vücut Tipinin Belirlenmesi (Somatotip)}

Somatotip, vücut tipi ya da insan vücudunun fiziksel sinıflandırması ile ilgilidir. Deneklerin somatotip değerleri Heath Carter yöntemiyle belirlenmiştir ve bulunan değerlerle vücut tipi belirlenmiştir?. Vücut tipi kategorileri şunlardır;

Endomorf: Endomorf baskın, mezomorf ve ektomorf yaklaşı eşit değerde ${ }^{10}$.

Ekto - endomorf: Endomorf baskın ve ektomorf mezomorftan daha yüksek değerde ${ }^{10}$.

Mezo - endomorf: Endomorf baskın ve mezomorf ektomorftan daha yüksek değerde ${ }^{10}$.

Mezomorf: Mezomorf baskın değerde endomorf ve ektomorf yaklaşık eşit değerde ${ }^{10}$.

Endo - mezomorf: Endomorf baskın ve mezomorf ektomorftan daha büyük değerde ${ }^{10}$.

Ekto - mezomorf: Ektomorf baskin ve mezomorf endomorftan daha büyük değerde ${ }^{10}$.

Ektomorf: Ektomorf baskın, mezomorf ve endomorf yaklaşı eşit değerde ${ }^{10}$.

Endo- ektomorf: Ektomorf baskın ve endomorf mezomorftan yüksek değerde ${ }^{10}$.

Mezo- ektomorf: Ektomorf baskın ve mezomorf endomorftan yüksek değerde ${ }^{10}$.

Endomorf; Vücut küresel bir görünümde, yuvarlak başlı, göğüs hizasından ileri çıkmış, yağlı büyük karınlı, üst kolu ve uyluğu fazla yağlı ancak ince bilekli penguen tipli kol ve bacaklıdır. Illk bakışta fazla yağlı görünen bu tipte yağlar, karın ve göğüste toplanmıştır ${ }^{1,2}$. kıvrım kalınlığ

$\mathrm{x}=$ triceps + subscapular + suprailiak deri

Endomorf $=-0.7182+0.1451 x-0.00068 x^{2}$ $+0.0000014 x^{3}$

Mezomorf; Kas ve kemik yapısı ileri derecede göze çarpan kübik görünümlü bir tiptir. Bu tiplerde baş gövdeye göre büyük, omuzlar ve gögüs geniş, kol ve bacak fazla kaslıdır. Kalp kası büyük ve az yağlıdır ${ }^{1,2}$.

$0.858(\mathrm{E})+0.601(\mathrm{~K})+0.188(\mathrm{~A})+0.161(\mathrm{C})-0.131$
$(\mathrm{H})+4.5$
E: Humerus epikondil çapı $(\mathrm{cm})$
K: Femur epikondil çapı $(\mathrm{cm})$
A: Biceps çevre - (triceps deri kıvrımı/10)
C: Uyluk çevresi - (uyluk deri kıvrımı/10)
H: Boy uzunluğu (cm)

(H) +4.5

A: Biceps çevre - (triceps deri kıvrımı/10)

$\mathrm{H}$ : Boy uzunluğu $(\mathrm{cm})$
Ektomorf; İnce, soluk benizli, geniş alınlı, dar göğüs ve karınlı, ince kol ve bacaklıdır. Yağsız ve kassız olmalarına karşın vücut kütlesine oranla geniş bir cilt yüzeyine sahiptirler ${ }^{1,2}$.

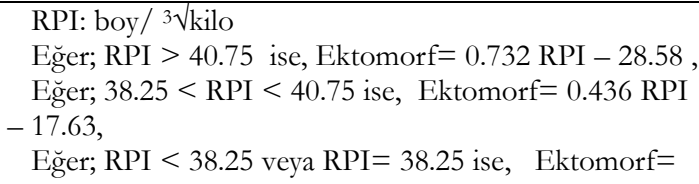

\section{İstatistiksel analiz}

Çalışmada sürekli değişkenler için tanımlayıcı istatistikler ortalama \pm standart sapma şeklinde özetlenmiş, kategorik değişkenler $\mathrm{n}(\%)$ ile verilmiştir. Verilerin normal dağılıma uygunluğu test edilip, duruma uygun olarak parametrik veya parametrik olmayan yöntemler seçilmiştir. Bağımsız grup karşılaştırmalarında "Independent- Samples t testi ve Mann-Whitney $U$ testi" bağıml grup karşılaştırmalarında ise "Eşleştirilmiş Student t testi ve Wilcoxon testi” kullanıldı. Anlamlılık düzeyi $\mathrm{p}<0.05$ olarak alındı. Çalışmada elde edilen verilerin istatistiksel analizleri için IBM SPSS version 19 paket programı kullanıld1 ${ }^{11}$.

\section{BULGULAR}

2013-2014 eğitim-öğretim yılında Çukurova Üniversitesi Devlet Konservatuvarı Bale Anasanat Dalı'na bale eğitimi için başvuran öğrencilerden $(\mathrm{n}=51 \mathrm{k} 1 \mathrm{z})$, bale eğitimine uygun bulunan öğrencilerin oluşturduğu deney grubu ( $\mathrm{n}=31 \mathrm{k} 1 \mathrm{z})$ ile uygun bulunmayan öğrencilerin oluşturduğu kontrol grubunun ( $\mathrm{n}=20 \mathrm{k} 1 \mathrm{z})$ çap, çevre, deri altı yağ dokusu kalınlığ1 ölçümü Tablo 2'de, somatotip analiz sonuçları, vücut tipi dağılımları ise Tablo 3, Şekil 1 ve Şekil 2'de özetlenmiş olup deney ile kontrol grupları kıyaslanmıştır. Araştırmanın veri toplama araçları vasıtasıyla çeşitli istatistiksel işlemlerden geçirilmiş sonuçları ortalama (ort) ve standart sapma (SS) değerleri ile tablolar ve grafikler halinde sunulmuştur. Uygun bulunan ve uygun bulunmayan öğrencilerin yaş, boy, vücut ağırlığ1, BMI ve çevre değerleri arasında anlamlı fark olduğu görülmüştür $(\mathrm{P}<0.05)$. Çevre ölçümlerinde uygun bulunmayan öğrencilerin değerleri daha yüksek bulunmuştur $(\mathrm{P}<0.05)$. Çap ölçümlerinde humerus çap1 parametresi hariç diğer parametrelerde uygun bulunmayanların değerleri daha yüksek olup anlamlı fark elde edilmiştir $(\mathrm{P}<0.05)$. Biceps, triceps, suprailiak, subscapular ve uyluk deri altı yağ dokusu 
kalınlığ1 ölçümlerinde ise uygun bulunmayanların değerleri daha yüksek olup anlamlı fark bulunmuştur $(\mathrm{P} \leq 0.001)$. Ektomorf ve mezomorf değerleri uygun bulunan öğrencilerde yüksek, endomorf değeri ise uygun bulunmayan öğrencilerde daha yüksek bulunmuş olup anlamlı fark elde edilmiştir $(\mathrm{P}<0.05)$.

Çalışmada uygun bulunan ve uygun bulunmayan öğrencilerin vücut tipleri belirlenmiştir. İki grup kıyaslandığında, uygun bulunan öğrencilerin \%45.2'si mezo-ektomorf iken uygun bulunmayan öğrencilerin ise \%45 i endo-mezomorf olarak bulunmuştur. Uygun bulunmayan öğrencilerde \%55 oranında endomorf vücut tipi hakimken uygun bulunan öğrencilerde \%45.2 oranında mezomorf vücut tipinin hakim olduğu sonucuna varılmıştır (Tablo 3).

\section{TARTIŞMA}

Bale sanatında balerinler estetik, zarif ve ince yapıda görünmelidir ${ }^{12}$. Literatürde Leon ve arkadaşları çalışmalarında, profesyonel bale dansçılarının vücut ağırlıkları ile beden kitle indekslerinin (BKI) halk dansçıları ve modern dansçılara göre daha düşük olduğunu göstermişlerdir ${ }^{13}$. Ayrica diğer dansçılarla kıyaslandığında bale dansçılarının zayıf ve düşük yağ oranına sahip olduğu, normatif verilerle kıyaslandığında ise daha ince ve daha uzun oldukları görülmüştür ${ }^{14}$. Klasik balede dansçıların kıdemlerine göre vücut kompozisyonları değerlendirilmiştir. Bu değerlendirmede solist profesyonel dansçıların topluluk dansçılarına göre daha düşük BKI'ye sahip olduğu gösterilmiştir ${ }^{14}$. Bizim çalışmamızda ise uygun bulunan öğrencilerin vücut ağırlı̆̆1 (VA) ve BKI değerleri uygun bulunmayan öğrencilerden daha düşüktür $(\mathrm{p}<0.05)$. Ayrıca çap ve çevre ölçümleri arasında da anlamlı fark çıkması $(\mathrm{p}<0.05)$ uygun bulunan öğrencilerin daha ince bir vücut yapısına sahip olduklarını destekler. Bennel ve arkadaşlarının, Avustralya'da yaptığı çalışmada, 8-11 yaş arası bale okulundaki kız öğrencilerde VA

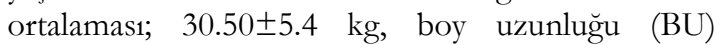
ortalamas1; $1.36 \pm 6.7 \mathrm{~m}$ ve BKI ortalamas1; $16.30 \pm 2.1 \mathrm{~kg} / \mathrm{m}^{2} \quad$ olarak kaydedilmiştir ${ }^{15}$. Çalışmamızda uygun bulunan öğrencilerin değerleri ile Avustralya bale okulundaki öğrencilerin değerleri benzerlik göstermektedir. Literatürde Blaes ve arkadaşlarının, 6-12 yaş arasındaki çocuklarda yaptıkları çalışmada BKI ve bel, kalça oranını sırasiyla; $17.1 \pm 2.5 \mathrm{~m}^{2} / \mathrm{kg}, \% 0.81 \pm 0.05{ }^{16}$, Özdirenç ve arkadaşlarının, kentsel ve kırsal alanda yaşayan 911 yaş arası çocuklarda yaptıkları çalışmada bel, kalça oranını sirasiyla; $\% 0.87 \pm 4.2$ ve $\% 0.89 \pm 4.9 \quad 17$, Mushtaq ve arkadaşlarının yaptıkları bir çalışmada ise 9 ve 10 yaş grubunda bel, kalça oranını sırasıyla; $\% 0.86 \pm 0.06$ ve $\% 0.84 \pm 0.06$ olarak bulmuşlardır ${ }^{18}$. Bizim çalışmamızda uygun bulunan öğrencilerde BKI ve bel, kalça oranı $\% 15.66 \pm 1.40$ ve $\% 81.91 \pm 4.03$ bulunmuştur. Çalışmamızda elde edilen BKI ve bel kalça oranı değerleri, literatüre göre daha düşük bulunmuştur ve bu durum bale eğitimi için gereken özelliklerin, çalışmamızda uygun bulunan öğrencilerde mevcut olduğunu destekler niteliktedir. Bale sanatında düşük bel, kalça oranına sahip olunması gerektiğini belirten Twitchett ve arkadaşlarının çalışması da bizim sonuçlarımızı desteklemektedir ${ }^{19}$.

Hergenroeder ve arkadaşları, profesyonel balerinlerde yağ stoklarının harcanması ve kas kütlesinin artması nedeniyle deri altı yağ dokusu kalınlığının kaliper ile ölçümünün yanıltıcı olabileceğini belirtmişlerdir ${ }^{20}$. Bu durumun farkındalığı ile bizde çalışmamızda henüz baleye yeni başlayacak adayların deri altı yağ dokusu kalınlığını (DAYDK) 5 bölgede ölçüp kontrol grubu ile karşılaştırdık. Ölçümler sonucunda uygun bulunan öğrencilerin deri altı yağ dokusu kalınlığı daha düşük bulunmuştur $(p<0.001)$. Uygun bulunan öğrencilerin bale eğitimi için uygun görülen vücut tipine sahip oldukları sonucuna varılmıştır. Uygun bulunmayan öğrencilerin ise DAYDK yüksek bulunmuş olup, bale eğitiminin gerektirdiği özellikleri bu doğrultuda karşılayamadıkları düşünülmektedir. Literatür taramalarına göre, Micheli ve arkadaşlarının, 1996 ve 2001 yıllarında, Boston'da 17-32 yaş aras1 profesyonel bale dansçılarında yapmış olduğu çalışmada, DAYDK ölçümlerini takip edip profesyonel bale hayatındaki değişimleri değerlendirmişlerdir. 1996 ve 2001 yıllarında DAYDK ölçümleri sirasıyla, biceps DAYDK; $4.8 \pm 2.1 \mathrm{~mm}$ ve $4.3 \pm 1.5 \mathrm{~mm}$, triceps DAYDK; $11.0 \pm 3.2 \mathrm{~mm}$ ve $10.2 \pm 2.7 \mathrm{~mm}$, suprailiak DAYDK; $7.1 \pm 2.7 \mathrm{~mm}$ ve $5.6 \pm 1.9 \mathrm{~mm}$, subscapular DAYDK; $8.5 \pm 2.4 \mathrm{~mm}$ ve $8.1 \pm 2.1 \mathrm{~mm}$, uyluk DAYDK; $15.4 \pm 3.9$ ve $14.0 \pm 3.4 \mathrm{~mm}$ olarak bulmuşlardır ${ }^{21}$. Aynı ölçümleri Hergenroeder ve arkadaşları, Haustan Bale Akademisi'ndeki yaş ortalaması $15.0 \pm 2.00$ olan balerinlerde yapmış ve triceps DAYDK; $10.9 \mathrm{~mm}$, suprailiak DAYDK; $8.90 \mathrm{~mm}$, subscapular DAYDK; $7.60 \mathrm{~mm}$ ve uyluk DAYDK; $15.20 \mathrm{~mm}$ olarak değerlendirmişlerdir ${ }^{20}$. Durakovic ve arkadaşlarının, Hırvatistan Bale ve Tiyatrosu'ndaki yaş ortalaması $30.8 \pm 6.36$ olan 30 profesyonel balerinde ise triceps DAYDK; 
$12.13 \pm 2.95 \mathrm{~mm}$, suprailiak DAYDK; $5.36 \pm 1.86 \mathrm{~mm}$ ve subscapular DAYDK; $7.00 \pm 1.61 \mathrm{~mm}$ olarak bulmuşlardır ${ }^{22}$. Çalışmamızda öğrencilerle profesyonel bale dansçılarının DAYDK ölçümleri yaklaşı olarak benzer sonuçlar gösterir. Balerinlerde profesyonellik arttıkça DAYDK değerleri azalmaktadır.

Özdirenç ve arkadaşlarının, Türkiye'de kentsel ve kırsal alanda yaşayan 9-11 yaş arası öğrencilerde yaptığ1 çalışmada, kentte ve kırsal alanda yaşayan kız ögrencilerin DAYDK ortalamaları sırasiyla; triceps ortalamalar1; $8.7 \pm 3.2 \mathrm{~mm}$ ve $7.1 \pm 1.4 \mathrm{~mm}$, suprailiak ortalamalar1; $5.2 \pm 2.7 \mathrm{~mm}$ ve $3.9 \pm 1.2 \mathrm{~mm}$, subscapular ortalamaları; $5.7 \pm 2.6 \mathrm{~mm}$ ve $4.8 \pm 1.2$ $\mathrm{mm}$ olarak bulunmuş olup ${ }^{17}$, çalıșmamızda uygun bulunan öğrencilerin DAYDK ortalamaları daha fazla bulunmuştur. Çalışmamıza dahil olan öğrenciler kentsel yaşam tarzına sahip olup, bu farklılı̆̆ın nedeni olarak kentsel ve kırsal yaşam tarzı farklılıkları gösterilebilir.

Optimal düzeyde bir dans performansı için beceri ve tekniğin her ne kadar önemli faktörler olduğuna inanılsa da, dansçıların gelecekteki performanslarını tahmin etmede tek başına yeterli değildir. Dansta performansı belirleyen önemli faktörler belirli bir vücut tipi ve vücut ağırlığıyla optimal vücut kompozisyonuna sahip olmaktır ${ }^{14,23,24}$. Çalışmamızda uygun bulunan ve uygun bulunmayan öğrencilerin vücut tipleri belirlenip, birbirleriyle kıyaslanmıştır. Ektomorf değeri uygun bulunan öğrenciler lehine, endomorf ve mezomorf değerleri ise uygun bulunmayan ögrenciler lehine sonuçlanmıștır. Uygun bulunan öğrencilerin daha zayıf ve daha az yağ dokusuna sahip olduğu bulunmuştur. İngiltere'de Livv ve arkadaşlarının yaptığı çalışmada yaş ortalamas1 $21.07 \pm 4.48$ olan profesyonel balerinler, modern dansçılar ve eşli dans yapanların endomorf değerleri sirasiyla; $3.59 \pm 0.84, \quad 3.79 \pm 1.07 \quad$ ve $2.72 \pm 0.67$, mezomorf değerleri sirasıla; $3.43 \pm 1.07$, $4.07 \pm 0.97$ ve $2.73 \pm 0.81$ ve ektomorf değerleri ise sirasiyla; $3.65 \pm 0.96,3.29 \pm 5.20$ ve $3.54 \pm 0.78$ olup, balerinlerin vücut tipini mezomorf olarak bulmuşlardır ${ }^{25}$.

Çalışmamızda bale eğitimine uygun bulunan ögrencilerin vücut tipi profesyonel balerinlere benzer olup uygun bulunmayan öğrencilerin \%55’i ise endomorf olarak değerlendirilip bale eğitiminin gerektireceği vücut tipine sahip olmadıkları bulunmuştur. Mersin Üniversitesi Devlet Konservatuvarı Bale Bölümü'nde yapılan 10-18 yaş arası kı öğrencilerin endomorf değeri; 3.18 \pm 0.96, mezomorf değeri; $3.53 \pm 0.92$ ve ektomorf değeri; $4.33 \pm 0.94$ olarak bulunmuştur ${ }^{26}$. Çalışmamızla kıyaslandığında endomorf ve ektomorf değerleri çalışmamızda uygun bulunan öğrencilere göre daha yüksek, mezomorf değeri ise daha düşük bulunmuştur. $\mathrm{Bu}$ farkın, bale okulundaki öğrencilerin adölesan dönemde olmalarından kaynaklandığ1 düşünülmektedir. Ferrari ve arkadaşları Bolshoi Tiyatrosu'ndaki 18-21 yaş arası bale öğrencilerinde yaptığ çalışmada ise baletlerde mezomorf ve balerinlerde ise ektomorf vücut tipinin baskın olduğu bulunmuştur ${ }^{1}$. Çalışmamızda uygun bulunan öğrencilerin vücut tipinin ektomorf ve mezomorf olduğu bulunmuş olup, bale eğitimi ile birlikte vücut tiplerinin şekilleneceği düşünülmektedir. Çalışmamızda cinsiyet faktörünün değerlendirilememesi ve katılımcı sayısının az olması

Uygun bulunan öğrencilerin vücut ağırlığı, BKI ortalamaları, çap, çevre ve deri altı yăg dokusu kalınlığı ölçümleri uygun bulunmayanlardan daha düşüktür $(\mathrm{p}<0.001)$. Bu sonuçlarda uygun bulunanların daha estetik ve ince vücut yapisina sahip olduklarını destekler niteliktedir. Uygun bulunan öğrencilerin vücut tipi mezo-ektomorf, uygun bulunmayan ögrrencilerin endo-mezomorf olarak değerlendirilmiştir.

Bu çalışmanın; bale eğitimi için öğrenci alımlarında gereken fiziksel özelliklerin belirlenmesine, çocukların bedenlerini tanımaları ve ailelerin farkındalığının artmasına ve bireysel bir eğitim planlanması ve gelişimlerinin takip edilmesine katk1 sağlayacaktır. Ayrıca fiziksel özellik olarak uygun olmayan bireylerin bale eğitimi almamalarıla olası sakatlanmaların önlenmesi hususunda faydalı olacağ1 düşünülmektedir. Bale eğitimi seçmelerinde, çalışmamızdaki test ve ölçümlerin kullanılması ve bale eğitimi seçmelerinde, bir anatomistin jüri üyeleri arasında yer alması önerilmektedir.

\section{REFERENCES}

1. Ferrari EP, Silva DAS, Martins CR, Fidelix YL. Morphological characteristics of professional ballet dancers of the bolshoi theater company. Coll Antropol. 2013;2:37-43.

2. Ergun N, Baltac1 G. Spor Yaralanmalarında Fizyoterapi ve Rehabilitasyon Prensipleri. Ankara, Pelikan Yayınevi, 1997.

3. Micheli LJ, Cassella M, Faigenbaum AD, Southwick $\mathrm{H}, \mathrm{Ho}$ V. Preseason to postseason changes in body composition of professional ballet dancers. J Dance 
Med Sci. 2005;9:56-9.

4. Ayvazoğlu S. Active dance life of ballet artists in turkey and their problems. Süleyman Demirel Üniversitesi Güzel Sanatlar Fakültesi Hakemli Dergisi. 2012;09:39-54.

5. Sürenkök Ö, Livanelioğlu A. The effects of classical ballet training on postural characteristics of lower extremity and lumbar region. Hacettepe Journal of Sport Sciences. 2001;12(3):25-31.

6. Hasan K. Edirne iline bağlı ilkokullardaki (şehit asım ilköğretim okulu ve trakya üniversitesi devlet konservatuvarı ilköğretim okulu) 8-11 yaş arasındaki ögrencilerin eurofit testleri ile fiziksel kondisyonlarının değerlendirilmesi (Yüksek lisans tezi). Edirne, Trakya Üniversitesi, 2008.

7. Lourens T. Anthropometric measurements of female adolescent ballet dancers. A research report. Faculty of Health Sciences. Johannesburg, University of the Witwatersrand, 2012.

8. Otman AS, Köse N. Tedavi Hareketlerinde Temel Değerlendirme Prensipleri. Ankara, Pelikan Kitabevi, 2014.

9. Köklü Y, Özkan A, Utku Alemdaroğlu, Ersöz G. Genç futbolcuların bazı fiziksel uygunluk ve somatotip özelliklerinin oynadıkları mevkilere göre karşılaştırılması. Spormetre Beden Eğitimi ve Spor Bilimleri Dergisi. 2009;7:61-8.

10. Carter JEL. The Heath- Carter Anthropometric Somatotype. San Diego, Department of Exercise and Nutritional Sciences San Diego State University, 2003.

11. IBM. IBM SPSS Statistics for Windows, Version 19.0 Armonk, NY: IBM Corp.

12. Milan KR. Injury in ballet: a review of relevant topics for the physical therapist. J Orthop Sport Phys Ther. 1994;19:121-9.

13. Leon HB, Viramontes JA, Garcia CMR, Sanchez MED. Study of the body dimensions of elite professional ballet dancers. Apunts Medicina de l'Esport. 2009;161:3-9.

14. Akyıldız M, Açıkada C. Sanat sergileyen sporcular olarak dansçılar: klasik bale dansçılarının fiziksel uygunluk bileşenleri. Hacettepe Journal of Sport Sciences. 2011;22:33-42.

15. Bennell KL, Khan KM, Matthews BL, Singleton C. Changes in hip and ankle range of motion and hip muscle strength in 8-11 year old novice female ballet dancers and controls: a 12 month follow up study. $\mathrm{Br}$ J Sports Med. 2001;35:54-9.

16. Blaes A, Baquet G, Fabre C, Praagh EV, Berthoin S. Is there any relationship between physical activity level and patterns and physical performance in children. Int J Behav Nutr Phys Act. 2011;8:122.

17. Özdirenç M, Özcan A, Akın F, Gelecek N. Physical fitness in rural children compared with urban children in turkey. Pediatrics Int. 2005;47:26-31.

18. Mushtaq MU, Gull S, Abdullah HM, Shahid U, Shad MA, Akram J. Waist circumference waist hip ratio and waist height ratio percentiles and central obesity amaong pakistani children aged five to twelve years. BMC Pediatr. 2011;11:105.

19. Twitchett EA, Koutedakis Y, Wyon MA. Physiological fitness and professional classical ballet performance: a brief review. J Strength Cond Res. 2009;9:2732-40.

20. Hergenroeder AC, Brown B, Klish W. Anthropometric measurements and estimating body composition in ballet dancers. Medicine Sci Sports Exerc. 1992;145-50.

21. Micheli LJ, Cassella M, Faigenbaum AD, Southwick $\mathrm{H}, \mathrm{Ho}$ V. Preseason to postseason changes in body composition of professional ballet dancers. J Dance Med Sci. 2005;9:56-9.

22. Durakovic MM, Matkovic BR, Ruzic L, Durakovic Z, Babic Z, Jankovic S et al. Body composition and functional abilities in terms of the quality of professional ballerinas. Coll Antropol. 2001;2:585-90.

23. Twitchett EA. Physiological demands of performance in classical ballet and their relationship with injury and aesthhetic components (Thesis of doctor of philosophy). Wolverhampton, University of Wolverhampton, 2009.

24. Steinberg N, Siev-Ner I, Peleg S, Dar G, Masharawi Y, Hershkovitz. Growth and development of female dancers 8-16 years. Am J Hum Biol. 2008;20:299307.

25. Livv H, Wyon MA, Jürimae T, Saar M, Maestu J, Jürimae J. Anthropometry somatotypes and aerobic power in ballet contemporary dance and dancesport. Med Probl Perform Art. 2013;207-11.

26. Arınlı Y. Adölesan dönemdeki bale öğrencilerinde beslenme alışkanlıklarının büyüme hormonu üzerine etkisi (Yüksek lisans tezi). Mersin, Mersin Üniversitesi, 2013. 